\title{
2007 CAEP/ACMU Scientific Abstracts Author Index
}

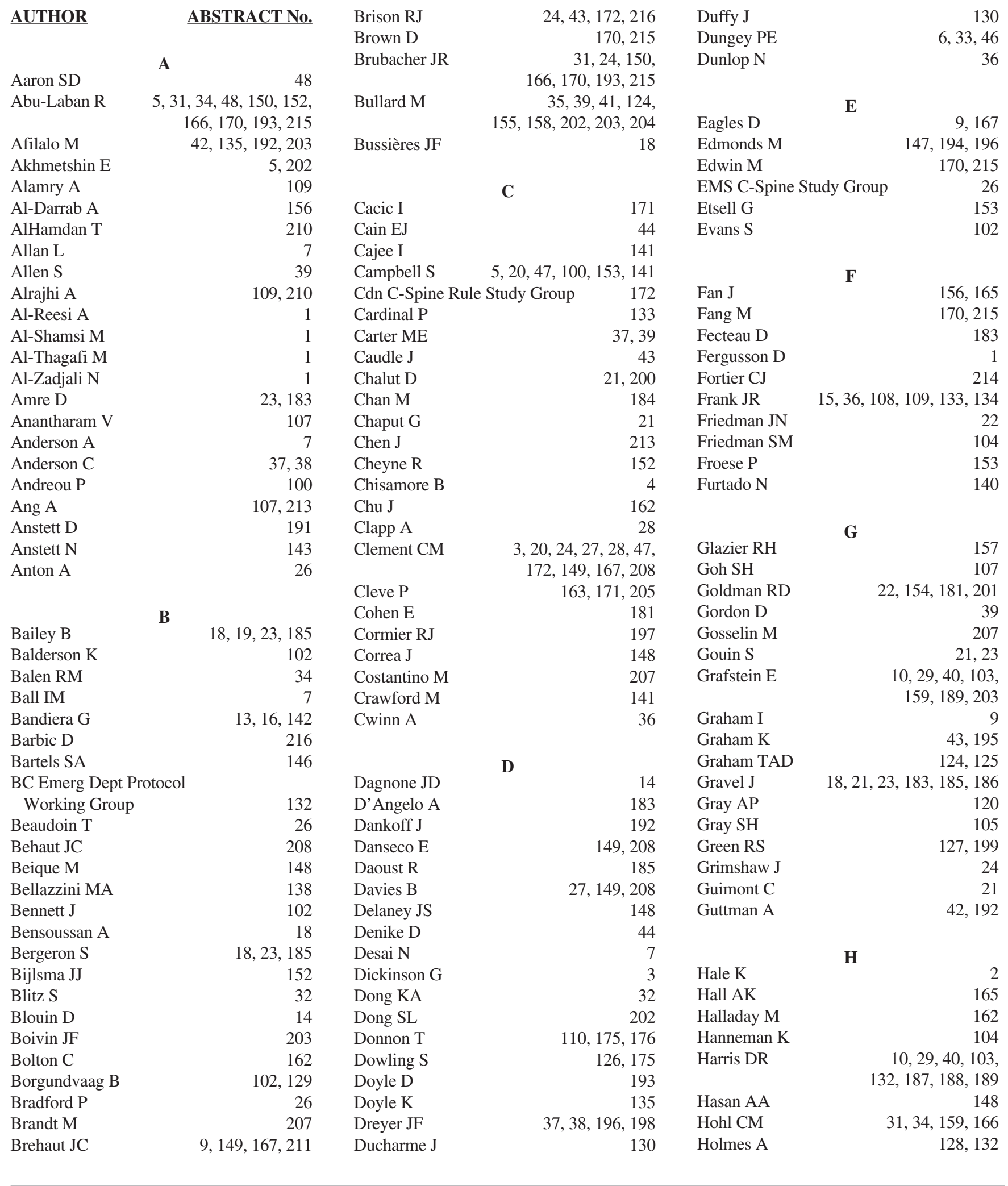




\begin{tabular}{|c|c|c|c|c|c|}
\hline Holroyd BR & $\begin{array}{r}35,39,41,155 \\
158,202,204\end{array}$ & $\begin{array}{l}\text { MacIntyre J } \\
\text { Mackenzie T }\end{array}$ & $\begin{array}{r}199 \\
27\end{array}$ & $\begin{array}{l}\text { Petrie DA } \\
\text { Phillips SJ }\end{array}$ & $\begin{array}{r}153 \\
187,188\end{array}$ \\
\hline Hung GR & 120,200 & MacKinley RP & 153 & Piggott Z & 43 \\
\hline Hurley K & 130 & Magee KD & 141 & Provan D & 104 \\
\hline \multirow[t]{2}{*}{ Hwang SW } & 13,142 & Mal S & 25 & Purssell RA & 170,215 \\
\hline & & Malik K & 181 & & \\
\hline \multirow[t]{2}{*}{ Innes GD } & $10,29,40,103$, & Martin E & 183 & Reed A & 162 \\
\hline & $132,189,206$ & Mason R & 106 & Rees E & 28 \\
\hline Innes KC & 128 & Matsui D & 184 & Rigby I & 175,176 \\
\hline Jarvis DA & 154 & Maunder R & 102 & Robidas I & 21 \\
\hline Jensen J & 164 & McCarney J & 132 & Romney M & 103 \\
\hline Joubert G & 184 & McIvor RA & 100 & Roy M & 23 \\
\hline \multirow[t]{3}{*}{ Joyce D } & 195 & McKnight D & 206 & & \\
\hline & & McLaughlin M & 159 & & $\mathbf{S}$ \\
\hline & $\mathbf{K}$ & McLeod S & 151 & Sampsel K & 195 \\
\hline Kaloupis P & 206 & McLeod SL & $37,38,196,198$ & Sargeant J & 130 \\
\hline Kapoor A & 201 & McRae AD & 147,194 & Sartor JR & 177 \\
\hline Kelly A-M & 167 & Mehta S & 201 & Schlichting AB & 145 \\
\hline Kennedy J & 127 & Mensah A & 25 & Schull M & $24,157,203$ \\
\hline Kerr J & 209 & Messenger DW & $6,46,33$ & Schwartz B & 106 \\
\hline Khambalia A & 22 & Meurer DP & 202 & Schwartzman A & 40 \\
\hline Khan Y & 157 & Michalski W & 122 & Scrivo C & 19 \\
\hline Laferrière C & 19 & & & Smart KL & 136 \\
\hline Lancee W & 102 & & & Snider C & $8,25,106$ \\
\hline Lang E & $131,135,192$ & Nanji A & 126 & Sobolev B & 150,166 \\
\hline Langhan TS & 110,176 & Nesbitt L & 20,47 & Sochaki K & 41 \\
\hline Latoszek K & $35,39,158$ & $\mathrm{Ng} \mathrm{KC}$ & 107 & Soucy N & 42,192 \\
\hline Leclair C & 27 & Nussbaum C, & 12 & Spence JM & 13,142 \\
\hline \multirow[t]{2}{*}{ Lee AC } & $12,15,136,108$ & O'Connor A & $27,149,208$ & Spinning C & 207 \\
\hline & $109,133,134$ & O’Neill C & 120 & Stacey M & 129 \\
\hline Lee $\mathrm{J}$ & 8,24 & OPALS Study Group & 20,47 & Steele S & 191 \\
\hline Lee $S$ & 17,137 & Osmond $\mathrm{MH}$ & 20,47 & Stenstrom R & $5,10,29,40$ \\
\hline Léger R & 42,192 & Ouellet C & 19 & & $103,127,159,189$ \\
\hline Lehnhardt K & 151 & & & Stiell IG & $1,2,3,5,9,20,24$ \\
\hline Leveck D & 122 & & & & $26,27,28,47,48,149$, \\
\hline Light $J$ & 28 & Page RJ & 140 & & $167,172,208,210,211$ \\
\hline Lin JY & 145 & Panylyk AH & 161 & Svenson JE & 212 \\
\hline Lindsay MP & 187,188 & Papa L & 28 & Symington $\mathrm{C}$ & 3 \\
\hline Loewen PS & 34 & Parker MJ & 182 & Szobota L & 195 \\
\hline \multirow[t]{3}{*}{ Lord J } & 175,176 & Parshuram CS & 182 & & \\
\hline & & Patrick G & 164 & & $\mathbf{T}$ \\
\hline & $\mathbf{M}$ & Peddle M & 151 & Taljaard M & 4,167 \\
\hline Ma W & 154 & Penciner R & 17,137 & Tam SL & $35,39,155,158,204$ \\
\hline Macarthur C & 22 & Perry JJ & 3,209 & Tan NC & 107 \\
\hline
\end{tabular}




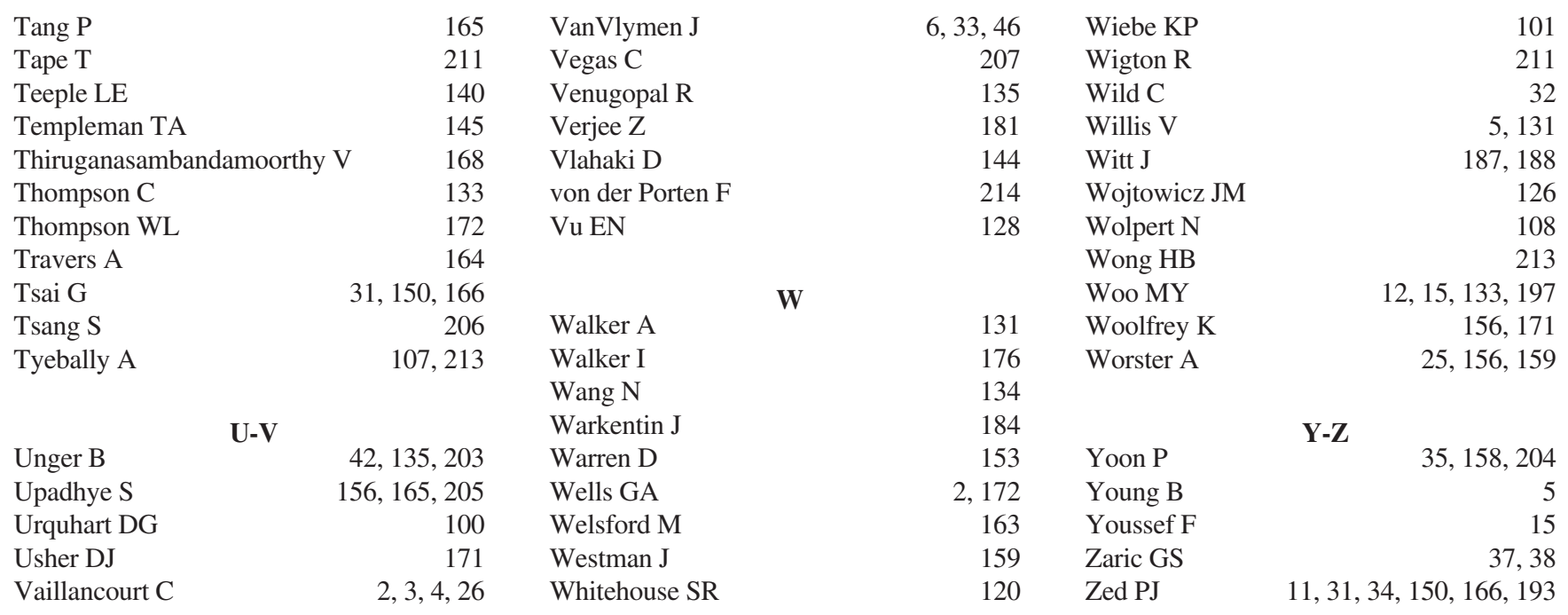

